\title{
Linguistic Analysis of Philippine Crime News Broadcasts
}

\section{William Mel C. Paglinawan}

Email : wpaglinawan@nddu.edu.ph University of Southeastern Philippines; Notre Dame of Dadiangas University

Article history

Received: 7 September 2021 Revised: 14 September 2021 Accepted: 30 September 2021

Keywords

Linguistic analysis Linguistic devices

Discourse strategies Crime news

Philippine broadcasts

\section{ABSTRACT}

News stories on negative phenomena such as crime news can stir diverse angles of reality which result in diverse forms of behaviors. This study examined the linguistic devices and discourse strategies employed by the Filipino Journalists in constructing crime news broadcasts. The Linguistic Analysis (LA) framework - using the lens of Ilya Romanovich Galperin and van Dijk's Socio-Cognitive Model were used; in which 25 mainstream crime news broadcasted in the Philippine TV from January to May 2015 were collected and transcribed. The findings revealed that phonetic devices such as alliteration, cacophony, assonance, rhyme and onomatopoeia were present in the corpus; lexical devices like epithet, metonymy, epigram, pleonasm, personification, and zeugma; and, syntactical devices such as enumeration, gap-sentence-link, asyndeton, rhetorical questions were mostly demonstrated in the sentences of the research corpora. Moreover, Filipino Journalists had utilized strategies such as, use of figures and statistics, metaphorization; authoritarianism; blame transfer; dysphemism; positive-self and negative-other; and source avoidance strategy. These devices and strategies made most of the statements contextual and implied. In addition, it was also revealed in the analyses that Philippine dialectical terms and neologisms were evident strategies used by the Filipino Journalist in assisting audiences to better appreciate, comprehend and discover the truth in news broadcasting.

This is an open access article under the CC-BY-SA license.

\section{Introduction}

Journalism writing dates back to the 17th century. The primary of any regular English newspaper was the Weekly News which first appeared in May 1622. The first English newspaper was principally a vehicle of data. Commentary found its way into the newspapers later than followed by news broadcasts. But as far back as the middle of the 18th century nation news publication and broadcast were substantially like what it is today — carrying foreign and domestic news, advertisements, announcements, articles containing comment, and even overseas and domestic news and even crime news which are broadcasted through televisions. The language in media and journalism is, "the same with the language of drugs, law, engineering etc. it's a wholly 
different language usage because journalists use their own quiet register that's only peculiar to the media profession. Crystal (1969) explained that "journalese" language is a very important aspect of journalism because it tends to be an explicit and precise barren of jargons. Considering its structure and construction, English journalese style is defined as a system of interrelated lexical, phraseological, and grammatical means which are perceived by the community as a separate linguistic unity (Crystal, 1969). Hence, elements of appraisal could also be observed within the very selection and way of the presentation of stories, within the use of specific vocabulary, casting some doubt on the facts recorded, and syntactical constructions indicating an absence of assurance of the reporter or his desire to avoid responsibility.

In the United States, Sacco in 1995 was the first to formally elaborate the effects of crime news to the individuals' private troubles and how this news is transformed into public issues. The development of crime news within the different multimedia may be understood as reflecting the kinds of relationships that link news agencies to their source and also the organizational constraints that structure the news-gathering process. While much attention has been focused on the ways during which media attention to crime influences the fear of crime, it's likely that the foremost significant effects of media reporting is broadly ideological instead of narrowly attitudinal (Sacco, 1995)

In the Philippines, news reports revealed that crime all over the country is rampant and continuously raging. The Philippine Star reported that crimes had amplified for around $46 \%$ during the midyear as compared to last year. This increase in the number of crimes committed is associated with the three main problems suffered by the Filipino people which are unemployment, poverty, and crime (Blace, 2014). According to the Philippine National Police (PNP), the crime volume became higher than that of the same period in 2014. Moreover, according to a news published in the Philippine Star, the 2015 data show that 631,406 crimes were reported and continuously increasing in the year before that, at 217,812 (Unson, 2015).

With this notion, if the crime rate is high, the security of the citizens is negatively affected. Apart from this, it also prevents economic growth and political development. News stories about these negative phenomena in society can stir diverse angles of reality and subsequently diverse forms of behaviors. Newswriting therefore must be done responsibly if it is to disseminate necessary information because the way of writing and relaying issues in the news has significant effects on the public's understanding and evaluation of the same. This study analyzed the devices and strategies incorporated in the news broadcast depicting crimes in the Philippine television and had answered the following:

1. What are the linguistic devices found in crime news broadcasts?

2. What are the discourse strategies employed by the Filipino journalists in writing crime news? 


\section{Method}

The Linguistic Analysis framework was employed in the corpus which analyzed the devices and the strategies in the crime news broadcasts. There were 25 gathered crime news broadcasts aired in various television networks in the Philippines from January 2015 to May 2015. These TV News Broadcasts were from CNN News Philippines, Al Jazeera News Philippines, BBC News PH and TOMONews PH. These corpora were analyzed using Ilya Romanovich (IR) Galperin (1977) Stylistic Devices. These devices were categorized by the researcher into three (3) linguistic levels. As shown in Figure 1, these linguistic levels were syntactical, phonetic and lexical devices. In addition, van Dijk's Discourse Strategies were also utilized in analyzing the approaches employed by the Filipino journalists in writing and broadcasting news.

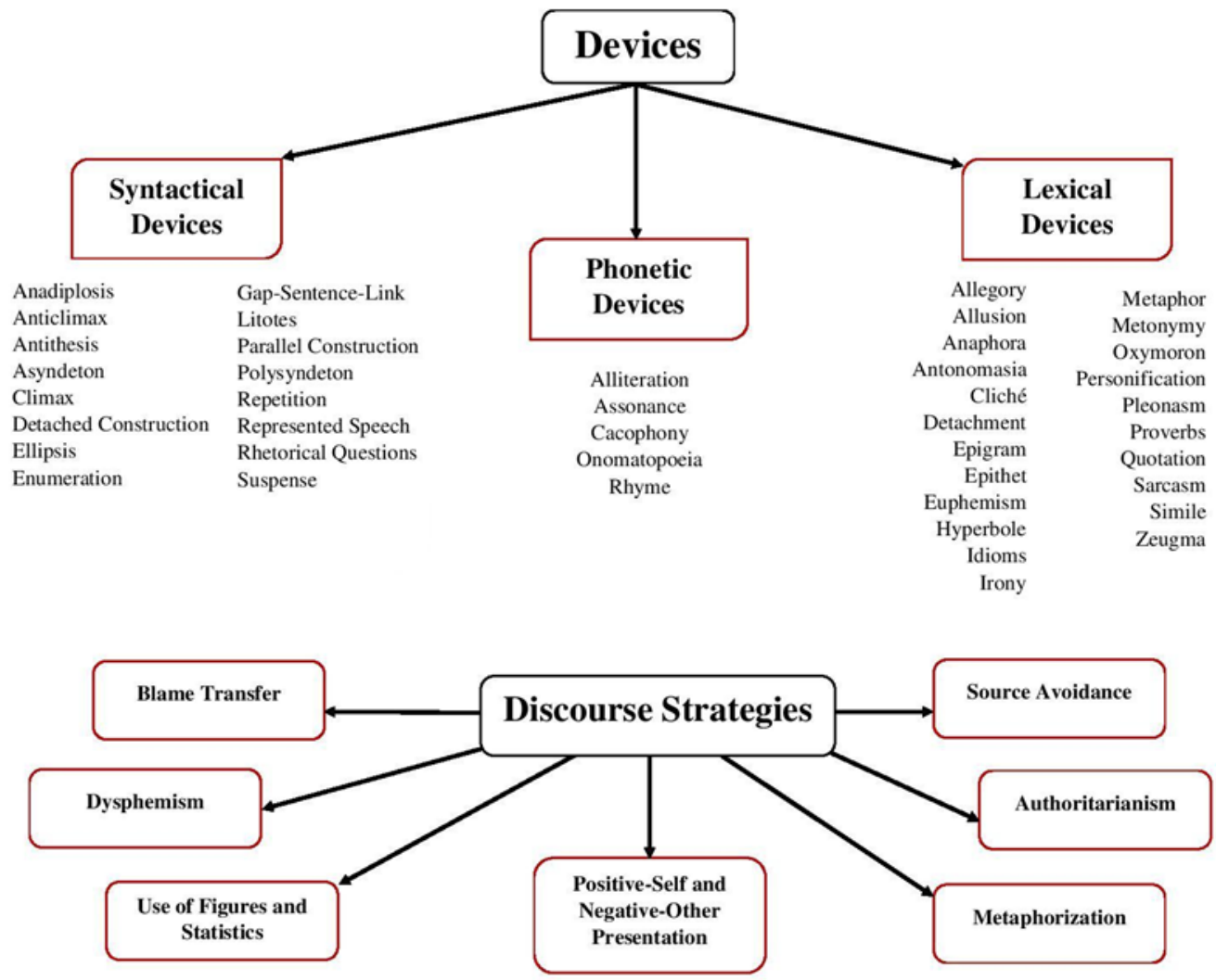

Fig. 1. Devices and Discourse Strategies

The study employed descriptive-qualitative methods in analyzing the devices and strategies of the corpus of crime news broadcasts in the Philippine television. In this study, descriptive-qualitative research was used since it is empirical to determine the underlying linguistic devices and discourse strategies in the corpus of 25 crime news broadcasts. Moreover, 
the study anchored the analysis of linguistic devices proposed by Galperin (1977) and the discourse strategies propounded by van Dijk (1955).

\section{Data Collection Procedures}

After the researcher had sought permission to conduct the study, there were twenty-five (25) crime news broadcasts collected and transcribed for analysis in this study. The crime news was broadcasted in the Philippine TV using English as the medium of news delivery. The selection of the corpus of crime news broadcasts followed a convenience sampling in which the corpora were selected for its accessibility and proximity (Battaglia, 2018). Furthermore, convenience sampling helped the researcher gather useful data and information. This sampling procedure is the preeminent method used for the selection of data for textual and literary analysis (Lavrakas, 2018).

In addition, the content of the crimes broadcasted were in congruence with the specifications under the 1930 Revised Penal Code of the Philippines. The gathered corpora were subjected for transcription and coding of episodes and these were then examined through linguistic analysis specifically by looking into the manifestations of the linguistics devices and discourse strategies proposed by Galperin in 1977 and van Dijk in 1955. The contention is that linguistic devices (as shown in Figure 1) were typically evident in poetry; hence the researcher would like to determine the demonstrations of these devices in prose such as in news broadcasts and how these devices affect meaning of text. Moreover, the discourse strategies were also investigated in order to corroborate how Filipino journalists presented the news stories.

\section{Finding and Discussion}

\section{Linguistic Devices in the Crime News Broadcast}

The analysis revealed the significance of devices and strategies construing the hidden meanings of news. Other phonetic, lexical and syntactical devices are also present in the corpus; however, they are rarely manifested in the lines and statements of the crime news broadcasts. Below are linguistic devices revealed in the study:

\section{Phonetic Devices Used in Crime News Broadcasts}

Phonetic devices, by nature, aim to create an effect on words, phrases and sentences' sounds (Galperin, 1977). Based on the analysis of the crime news broadcasts, alliteration and cacophony are the devices perceptible in the corpora of the study. Devices such as assonance, rhymes and onomatopoeia were also manifested in the crime news broadcasts. 
Sample \# 1 Pork Barrel Scam as the biggest single scam scandal in Asia... (CNN News Philippines, January 8, 2015)

Sample \# 2 He sold a hundred handguns over the past year (Al Jazeera Philippines, January 10, 2015)

According to Mantra (2021), alliteration is the repetition of a speech sound in a sequence nearby. Alliteration is usually used by companies or people to make the name easy to memorize. In analyzing the two excerpts from the sample corpora, the passages have alliterations with /s/ and $/ \mathrm{h} /$ sounds. These sounds were formed through alliteration to elicit danger and violence, which describe the crime situation. It is also regarded as an emphatic phonetic (Galperin, 1977) that aims at producing a strong melodic and emotional effect among the audience.

Alliteration is a method of euphonic repetition in one voice, tuning one or two similar sounds. It is a musical unity of the author's thought in showing ideas or messages. For alliteration to be effective, alliteration words must be consistent. If there are too many non-alliterative words, then the medium is not fit for purpose (Nizomova, 2021).

Cacophony is another phonetic device found in the study. It is evident in the samples gathered that Filipino journalists also consume the use of cacophonic sounds. According to the Sound Theory, as discussed in the study of Pathak, Calvert \& Motoki (2021), explained that words with outwards articulatory patterns are expected to be sweet and round. Whereas, words with inward articulatory patterns are expected as bitter and sharp. Hence, it can be concluded in the results that the presence of cacophony denotes bitter sound-meaning which is suitable for crime news.

Sample \# 3 ... Southeast Asia's most powerful rebel group... (Al Jazeera Philippines, February 12, 2015)

As presented, the phrase used the consonant combinations of $/ \mathrm{p} /$ for "powerful", $/ \mathrm{r} /$ for "rebel", and /g/ sounds for "group". These sounds are called plosives (Galperin, 1977), which are used to describe the terrorist and which denote danger among the citizens. According to Galperin (1977), the uses of "plosives" or harsher sounds are formed by the combination of /b/, /d/, hard /g/, / k/, /p/, /t/. These plosive sounds are the fundamentals of cacophony.

This is further supported by Pathak, Calvert \& Motoki (2021), stating that inward articulations such as plosives $[\mathrm{p}, \mathrm{b}, \mathrm{t}, \mathrm{d}, \mathrm{k}, \mathrm{g}]$ which have also been shown to affect the perceived 
meaning of words. According to Galperin (1977) combining these sounds can increase tension, conflict, or disharmony of ideas expressed in both poetry and prose.

In order to describe the destructive effects of crimes in the Philippines, the journalist makes use of cacophonic sounds in news broadcasts to portray discomfort of some unpleasant situation that the news broadcast is describing. Thus, this indicates that Filipino journalists use unpleasant sounds of a cacophony primarily to communicate or invoke negative emotions such as disgust, distress, violence or fear.

Smith in 2010 defined assonance, as revealed in the analysis of the corpus of the study, imparts melodic effects to an utterance through the pairing and repetition of vowel sounds.

Sample \# 4 ... Pornsites showing children rose by over 300\% since 2011 according to government data. (BBC News PH, February 22, 2015)

The sample is a line from the news broadcast having the repetition of the vowel sound /o/. It can be said that assonance is used mainly to produce specific sound combinations that trigger literary or auditory associations in listeners and audiences. One main use of assonance is to help the text "flow" mainly from an auditory perspective (Galperin, 1977). As presented, the assonances stated, exploit the use of /o/, /J/, /I/ and /i/ sounds. Makhsetbaevna (2021) mentioned that the repetition of vowels is vertical and horizontal and plays an important role in the formation of phonetic-semantic connections.

Through lexical repetition, the author can turn a message into emotionally charged speech. Using the same repetition, the listener's attention is drawn to the word in that repetition. Hence, the use of agreeing sounds to highlight important words will trigger and provide "clues" for mood and symbolisms.

Rhyme and Onomatopoeia, based on analysis, is also evident in the corpora of crime news broadcasts.

Sample \# 5... the girl who suffered whiplash injuries ... (TomoNews Philippines, April $23,2015)$

The excerpt is a sample of onomatopoeia which contains the consonant phoneme $/ \int /$ or "sh" (same effect with /s/) which indicates a hissing sound (Galperin, 1977). Onomatopoeia, according to Muslima (2021), can form new meanings in a sentence. This device can also be an explanation and giver of an imagination and new thoughts that come from a sentence.

According to Duan and Xu in 2020, rhymes and onomatopoeia aim to teach listeners and audiences about the physical characteristics or a specific living environment. Looking at the sample statement from the crime news broadcasts, this device plays an important role in 
understanding the storyline for it links to a sensory experience. In this study, this sound, though soft and smooth, symbolizes harshness, violence, cruelty, discomfort, noise or conflict.

Sample \# 6...Cabrera is suspected of strangling the girl and beating her unconscious. (TomoNews Philippines, April 23, 2015)

Upon examining the passages, the words "strangling" and "beating" appeared to be rhymes. "Strangling" and "Beating" are words having two syllables and expressing a similar final sound /ing/. Looking at the rhymes, it can be noticed that a stressed syllable is followed by an unstressed syllable. It can be implied that rhyme is not just another decorative phonological feature and are not limited in deepening the characteristics text; but it also gives a comprehensive picture of the context (Nastenko, 2021).

The regular recurrence of sounds is ideally a source of pleasure for the ear and will create atmosphere in text; however, the rhymes are used in the corpus to set an atmosphere, which describes a crime situation. According to Galperin (1977) what is common among rhymes is that all of them implicate a solid amount of force and energy, with strangling and beating, harmful and disruptive impacts among audiences.

\section{Lexical Devices Used in Crime News Broadcasts}

Lexical Devices as elaborated by Galperin (1977) proved that these devices are used to create expressive, evaluative and subjective connotations by manipulation of meaning whether by intensification or interaction between word's meanings. Based on the analysis of the corpus of crime news broadcasts, the dominant lexical devices are epithet, metonymy, epigram, idioms, pleonasm and zeugma.

Sample \# 7 ... the accused politician was charged with corruption along with two other senators were from opposition, including the son of former president Joseph Estrada... (Al Jazeera Philippines, January 5, 2015)

By definition, epithet is defined as a descriptive phrase expressing a quality characteristic of the person or thing mentioned. The passage has an epithet to describe family ties. Looking at the sample extract from the crime news broadcasts, the phrase "son of former president" denotes that one of the sons of former Philippine President Joseph Estrada who currently assumes political position is charged with corruption. According to Mokhathi-Mbhele (2020), these are classified to as interpersonal epithets which mostly are adjectives of size, quality and age. Looking at the sample, this gives the audiences the impression that personalities implicated in crimes are commonly described as politicians and people with high standard and status of living. 
Sample \# 8...the Mayor is seeking the generous hand of the national government... (CNN News Philippines, January 8, 2015)

Metonymy also refers to the part for the whole; there are many parts that can stand for the whole. As revealed in Sample 8, "The Mayor is seeking the generous hand of the national government" uses hands to refer to an alliance and aid. Furthermore, the point of using metonymy is not just to use a part (hand) to stand for a whole (alliance and aid), but also to highlight particular characteristics of the person such as support, generosity, charity and help which is associated with the part (hand).

In the book Lakoff and Johnson in 2008, as cited by Golovko (2019), metonymy has always been described as conceptual rather than purely linguistics. Metonymy therefore is a device that consist of using the name of one thing for that of something else with which it is associated.

In addition, the Epigram is defined as a brief, clever, and memorable statement. Some of them are formulated with satirical purposes in mind, and others are purposely meant to reveal deeper meaning. Galperin (1977) explained epigrams caused the reader or listener to think a bit more about the statement being made and leave an impression.

Sample \# 9...the scars will be with him long after the marks have faded... (Al Jazeera Philippines, January 22, 2015)

This sample reveals that in spite of the years past long after the crime happened, the painful memories brought by these crimes remain. Fowler (1991), as cited in Croft (2018) describes epigram as a clever and witty statement expressed in just a few lines (Galperin, 1977), pointing out foible and truths of mankind. This implies that Filipino journalists use this lexical device to expose and reveal the reality of life. The main purpose of using such statements is to leave an impression on the audience, as journalists demonstrate pure wit coupled with wisdom, these devices will cause the audiences to think deeply about the meaning behind statements.

Sample \# 10 ...Philippine troupes have killed at least 37 Islamic Fighters and captured a rebel stronghold on Thursday in a two-day offensive against insurgents... (TomoNews Philippines, January 13, 2015)

An expression like "Islamic Fighters" simply is accepted as synonymous with "insurgents". These pleonasms are just long-winded wordiness like a sentence that includes far more words than is necessary. In the study of Iswati and Widodo (2020), pleonasm is the redundant use of words in a phrase or sentence which deliberately have the same meaning. This device is used on purpose and that is to reinforce meanings. 
In this paper, this device functions as a tool by journalists to emphasize something or clarify an idea through repetition. This helps audiences remember main ideas as they listen or read.

Zeugma is another lexical device apparent in the corpora of the study. This device is used when two or more related words are presented (Galperin, 1977).

Sample \# 11 ... Just like their fathers they are uneducated, poor and marginalized... (Al Jazeera Philippines, April 14, 2015)

Zeugma is an important linguistic device, wherein a single word is used to denote two or more words in a sentence and is fraught with literal and metaphorical undertones (Nurmamatovich \& Abdurashidovna, 2021). Looking at the sample, it can be implied that without proper education and training, a person is dubbed as uneducated. A person who is underprivileged from his right to live and to meet basic needs is considered poor. If a person is treated inferior in society, they are called the marginalized.

According to Timralieva, J. G. (2021), zeugma as a linguistic device, is used mostly as means conveying strong emotional states characterized by semantic multilayering and intensity of expression. In this paper, the terms uneducated, poor and marginalized are different in terms of its lexical meaning; however, when used in the passage, shared a comparable semantic relation.

Sample \# 12 ... The UN warning is more serious than China stealing the Spratly Islands. (CNN News Philippines, January 8, 2015)

Personification, according to Galperin in (1977) is another linguistic device which describes the act of giving non-living things human characteristics. The sample uses a verb "stealing" which gives the inanimate idea "China" a life which denotes feelings, mood and actions. With this, the audiences would realize that similar in a human situation, various people are yearning to be in possession of something beyond their ownership.

Based on these results, it can be concluded that the use of personification is common and found in many lines in the corpus of crime news broadcasts. Personification is usually used to beautify a text. By using personification, the writer can convey the message aesthetically with the hope that it can be easily received and understood by the readers (Muthalib, Fata \& Rohaza, 2020).

It is manifested in the corpus that Filipino journalists rely on personification to bring inanimate things or ideas to life, so that their nature and actions are understood in a better way since it is easier for the target audience to relate to something that is human or that possesses human traits. 


\section{Syntactical Devices Used in Crime News Broadcasts}

Syntactical devices are used to analyze the internal structure of sentences in a language and the way they function in syntactical sequences; clauses, phrases, words, nouns, verbs, etc. (Fengjie, 2016). These devices are also used to effectively carry out the function of crime news broadcasts. Results showed that the journalists used the syntactical devices such as enumeration, gap-sentence-link, asyndeton, and rhetorical questions frequently.

Enumeration is commonly used to list names, examples, specifications and descriptions. Enumeration, as explain by Galperin (1977), is a linguistic device, which separates things, properties or actions brought together and forms a chain of grammatically and semantically homogeneous parts of the utterance

Sample \# 13 ... Pakistan, Somalia, North Korea, and Iraq are the only countries ahead of the Philippines... (CNN News Philippines, January 8, 2015)

This is used as a rhetorical device to break a topic or argument down into component parts, or to list details of the subject one by one (Kholod, 2021).

The list of countries presented in the sample is enumerated to provide examples of similar countries whose corruption cases are, more or less, as extensive as the Philippines. Given this, the audiences are told that the Philippines is not the solitary country who suffered the wrath of graft and corruption.

This gives audiences the perception that crime such as corruption is not only a local and national predicament but also it is a global phenomenon which is suffered by countries primarily belonging to the Third World Nation.

From the given sample, it is implied that enumeration simply provides additional information and clarity by breaking an action down into specifications. This breakdown can give information, show cause and effect, predict events and describe specific actions.

Sample \# 14 When shootings are as common as they are in Tondo, Manila's most dangerous slum, another funeral doesn't get much attention. (Al Jazeera Philippines, January 10, 2015)

The passage illustrates the usage of gap-sentence-link (GSL). The statement is divided into three important ideas such as "when shootings are as common in Tondo," "Tondo Manila is the most dangerous slum," and "Another funeral does not get much attention." In this sentence, the ideas do not use any conjunction but employ the use of punctuation. 
These breaks in the sentences, at first, are difficult to understand; however, this will give audiences a subjective evaluation that Tondo in Manila is one of the places in the Philippines which is perilous to visit.

The results also showed that the crime news broadcasts used asyndeton. Asyndeton is a syntactical device used to intentionally eliminate conjunctions between the phrases and in the sentence, yet maintain the grammatical accuracy. This linguistic device helps in reducing the indirect meaning of the phrase and presents it in a concise form (Chiluwa \& Blench, 2016).

Sample \# 15 Daily shootings sometimes between rival gangs, like this one captured on a security camera, shows the little decurve the violence. (Al Jazeera Philippines, January $15,2015)$

The sample illustrates that journalists use asyndeton to speed up a passage and propel a reader toward a conclusion. This may happen in scenes where there is much action in the plot so as not to be bogged down in details. The use of asyndeton can also be to highlight the connection between words or concepts to show how they are related (Adams, 2021). In the sample provided, it implies that the idea of frequent daily shooting is related to the uncountable incidents of violence in the Philippines.

Sample \# 16 Why is it the victims of these killings are only those opposed the mayor? (BBC News PH, March 2, 2015)

The passage revealed a rhetorical question. Thacker and D'Angelo (2019), explained that rhetorical question is usually designed to speak directly to the reader. It allows the reader a moment to pause and think about the question. The author of the passage above grasped the audiences in a way that subtly suggests that the reader does not know the reason behind the culture of impunity in the Philippines. Hence, the question stipulated in the excerpt appears to be rhetorical or symbolic provided that the journalist merely wants the audiences to follow a logical chain through critical reaction.

\subsection{Discourse Strategies in the Crime News Broadcasts}

The discourse strategies featured in the Philippine Crime News Broadcasts include figures and statistics strategy as the most commonly used strategy. This is followed by metaphorization strategy, authoritarianism strategy and blame transfer strategy which are more commonly used strategies.

Sample \# 17 The report listed the Pork Barrel Scam as the biggest single scam scandal in Asia in the last 10 years which involves an estimated amount of $\$ 222.7 \mathrm{M}$ or for about P10 Billion. (CNN News Philippines, January 8, 2015) 
The journalist, in writing the passage above, used Figures and Statistics Strategy. The figure such as $\$ 222.7 \mathrm{M}$ or about P10 Billion is used as an emphasis to the crime presented. This figure highlighted the amount of money swindled and defrauded by government officials involved in the Pork Barrel Scam.

Using data such as figures and statistical fact, allows the journalists shift its main focus from being the first ones to report to being the ones reliable of the report (Lorenz, 2018). Hence, figures and statistics are used when trying to argue for or prove something in an article. A journalist includes documented statistics to back up his or her beliefs or arguments.

Based on the analysis of data, van Dijk (1955) explains that figures and statistics are used when trying to argue for or prove something in an article. In this excerpt, a journalist includes documented statistics to back up his or her beliefs or arguments. The statistics also help give the article and the journalist's credibility; thus, once the journalist is credible enough in giving information to the public, the audiences will then encompass their trust.

Sample \# 18 Birth pains or not, Bred says the scars will be with him long after the marks have faded. (Al Jazeera Philippines, January 22, 2015)

The underlined word "scar" above was used metaphorically to deepen the presentation of the message. The word "scar" denotes the distressing incidents to evoke what had happened. According to Pervukhina and Rood (2021), metaphors are not merely part of the language. In fact, these devices shape the very way in which people think. With this, metaphors allow writers to convey vivid imagery that transcends literal meanings, creates images that are easier to understand and respond to than literal language.

Metaphorical language activates the imagination, and the writer is more able to convey emotions and impressions through metaphor (Cameron, Pelosi, \& Feltes, 2014). This was further explained by Cameron in 2018 stating that the use of metaphor allows writers to present unfamiliar ideas or situations in ways that the reader is able to comprehend by comparing unknown things to known things. Metaphors can also be used, however, to compare very common things to one another. This type of usage forges a cognitive link between previously unrelated objects and makes audiences appreciate them in a new way.

Furthermore, another strategy exploited by the Filipino journalist is the authoritarianism strategy.

Sample \# 19 Louie Oppus, the newly appointed head of the Police Firearms Division, admits corruption in the force is a problem. (TomoNews Philippines, March 22, 2015) 
The sample was an excerpt taken last March 22, 2015 broadcast from TOMONews Philippines, which broadcasted about the rampant gun violence in the country. As elaborated in the crime broadcast, one of the main angles being investigated was the corruption within the Philippine Firearms Division is apparent. With this, Louie Oppus served as authority who confirmed that anomalies inside the PNP office are perceptible. As presented in the broadcast, Oppus stated that weapons seized by authorities and kept in the storehouse, were also stolen and resold in the black market.

This strategy is used to emphasize the reliance on officials, prominent people and other authorities as primary sources of information. This means that reliance on public officials would establish facts to the public. Mass audiences deserved to be informed with the latest news in the society - this is part of the so - called media responsibility.

In addition, in these modern times, because of the advancement of social media platforms, fake news relating to different purposes has been increasing day by day. Hence, establishing a concrete bases for news writing and deliberately in quest of legitimate source of information have become an important part in improving the reliability of news to detect fake news efficiently and on time (Harjule, Sharma, Chouhan, \& Joshi, 2020).

Moreover, the representation of how blame is allocated always follows when there is crime. Crimes and other related phenomena seem to be destructive, but they do not just occur without contributory causes. Further, it is interesting to know who earns the blame on these crimes and how they are ascribed in the course of crime news broadcasting. Hence, Filipino journalists also make the most of blame transfer strategy.

Sample \# 20 Prosper Slachmuylders is a former mayor from Belgium, he is also accused of child pornography. (BBC News PH, February 22, 2015)

Sample \# 21 Marwan... wanted for the murder of a Christian member of parliament in Malaysia, he was also one of the suspects behind the bombing of tourists in Bali in Indonesia. (TomoNews Philippines, April 23, 2015)

In the samples, the personalities such as Prosper Slachmuylders and Marwan, are identified as the actors. The process is realized by the verbal group - is also accused, wanted, have made and were arrested and directed at the goal- of child pornography, murder of the Christian member, made matters worse, and of alleged bodily injury respectively.

Upon examining the structure of the sentences, it can be implied that the actors are the participants responsible for the crimes. In the passage, "Prosper Slachmuylders ... is also accused of child pornography" means that this Belgian national and politician is an agent liable of the charges on child trafficking and pornography and children engaged re unrepentant of the crime. 
"Marwan... he was also one of the suspects behind the bombing in Bali Indonesia." The passage reveals that the actor is blamed for the bombing of tourists in Indonesia. However, it is not explicitly stated that the peace and order in the Philippines is not reaching its maximum result. Hence, the government is also legally responsible for the said crime case. Thus, employing blame transfer strategy will also reveal other implied entities such as social, economic and political factors which also to be blamed on such crimes.

Spriggs (2020) states that when blame is used as a political tool, it tends to have a much harsher effect - thus, blame is never just a tool and it is never harmless. With this, looking at the samples previously presented, blame strategy singles out individuals and specific violations of moral standards. Considering the crime news broadcast examples, the antagonist was blamed for critical events and their negative outcomes, and the antagonist now bears the responsibility for said outcomes (Labov, 2004, as cited by Spriggs in 2020).

Adding to what has been discussed, apart from the devices present in the corpus of crime news broadcasts and the strategies employed by the journalist in presenting the details of the crime news, there are some evidences on the existence of the usage of Philippine English Dialectical Words and Neologisms in the corpora of the study.

The Philippines has some hundred indigenous languages, most only a small number of speakers. However, the major languages have millions of speakers and cultural borrowings especially in the area of food, clothing and religion are extensive. Based on the analysis of the corpora of the study, data revealed the use of dialectical words or terms, which manifested in crime news broadcasting.

Sample \# 22 It was a dispute between warring clans here, a century's old practice called Redo. (Al Jazeera Philippines, March 12, 2015)

The word "redo" is an Islamic term, which defines a dispute between warring clans or family. Hence, this term can be classified as a dialectical word. As defined, dialectical word is a word term, which still undergoes in the process of integration of the English national language, remains beyond its literary boundaries and their use is generally confined to a definite local (Chiluwa \& Blench, 2016).

Sample \# 23 A shootout in the heart of a bustling Southern-Philippine city. (CNN Philippines, February 13, 2015)

By definition, shootout means to emit or spit out. However, as the term used in the sentence, shootout refers to the exchanging of fires between the Philippine army and the insurgents. The existence of this term is evidence that Philippine English exists in almost all forms 
of written and oral discourse. Moreover, according to the study of Chiluwa and Blench (2016), one of the most difficult issues in lexicography is documenting usages in a semi-written language. If dictionaries of indigenous languages are prepared, they usually depend entirely on oral sources and thus no specific justification is given for entries. However, Philippine English is sometimes written, especially in newspapers and magazines, and thus, has some sort of orthographic tradition. 2015)

Sample \# 24 Philippines busts global online sextortion ring (TOMONews, February 28,

The term "sextortion" is a compounded term derived from the terms sex and extortion. This phenomenon is called neologism. By definition, neologism refers to the unprecedented explosion in the invention and spread of new words. In this study, it was revealed that Filipino journalists have utilized word-formation in the form mostly of nouns and adjectives.

In the study of Asif, et al. (2021), neologisms present colorful portrayals of various social and cultural practices of respective societies. Similarly in this study, some neologisms were derived from socio-cultural lexicons. Although varieties of English are generally acceptable for a wide range of purposes, they are yet to reach a stage of standardization in most cases. Hence, varieties of English have only intelligibility, acceptability and interpretability as standards (Croft,2018).

\subsection{Synthesis of the Results and Discussion}

Looking at the interpretations and analyses of data, the results of the study showed that the crime news broadcasts maximize the usage of linguistic devices in presenting crime issues in the news broadcasts. These are manifested in the lines of the news broadcasts. Specifically, in terms of phonetic devices, the study examined five (5) phonetic devices, in which the most evident devices are alliteration, cacophony and assonance. On the other hand, rhyme and onomatopoeia are the devices, which rarely appeared in the corpus understudied.

Based on the analysis of data, only a few lines in the crime news broadcasts showed these phonetic devices since the journalists concentrated on the structure and meaning of sentences and its implications to the readers, thus not fully utilizing the entire devices. There were different lexical devices apparent in the corpora. The results revealed that the lexical devices frequently appearing in the corpora of the study are epithet, metonymy, epigram, pleonasm, personification, and zeugma. The other lexical devices such as allegory, allusions, anaphora, cliché, among others (Refer to list on Figure 1) are also present in the corpus however, they are rarely manifested in the lines and statements of the crime news broadcasts. 
In addition, upon analyzing the eighteen (18) syntactical devices in the corpora of the study, results demonstrated that enumeration, gap-sentence-link, asyndeton, and rhetorical questions are the most apparent syntactical devices in the corpora. Other syntactical devices such as anadiplosis, anticlimax, antithesis, ellipsis and some others (Refer to Figure 1) are also present; however, they are rarely manifested in the lines and statements of the crime news broadcasts.

On the other hand, it was also found out that Filipino journalists had exploited different discourse strategies proposed by van Dijk in 1955 in presenting crime issues in the news broadcasts. These strategies were used to influence socio-political views in a way that readers' perception and actions had been mustered and framed. In particular, among the seven (7) strategies apparent in the crime news broadcasts, use of figures and statistics strategy is the most commonly used strategy. This is followed by metaphorization strategy, authoritarianism strategy and blame transfer strategy which are more commonly used strategies. Lastly, results revealed that dysphemism, positive-self and negative-other strategies and source avoidance strategies were the least commonly used strategies employed by the journalist in the news broadcasting

\section{Conclusion}

Data revealed that linguistic devices were evident in the research corpora for specific purposes. These devices proved to be effective agents to strengthen arguments and news details and intensify mass involvement. For a topic as substantial as the Philippine Crimes depicted in the news broadcasts, the linguistic devices function to institute the desired effect that the journalists intend for their audiences to obtain. The mood, the tone and the meaning were determined by the successful use of the phonetic, lexical and syntactical devices. Another observable function of the linguistic devices was the materialization of implications that must be perceived by the audiences. Using these devices, most of the statements and details were contextual and implied; however, some were expressly and deliberately written and broadcasted.

It was also found out that only a few lines in the corpora have revealed phonetic devices since the journalists concentrated on the structure and meaning of sentences rather than the more of the utterance. Similarly, other lexico-syntactical devices were not manifested in the crime news or rarely used by the Filipino journalist because these linguistic devices like allegory, allusions, anadiplosis, and anticlimax, among others were used in poetry rather than on prose such as in news and broadcasts. Various messages and meanings have been corresponded through news broadcasts. It was revealed in this study that journalists influence opinion, mobilize actions and persuade people's perception through various discourse strategies. Hence, the significant data obtained using linguistic analysis of discourse strategies have aided news readers to discern the truth and reality in news broadcasting. 
Apart from the devices and strategies investigated in this study, the results of the linguistic analysis also revealed the usage of Philippine English such as the integration of dialectical words and neologisms in writing the crime news broadcasts. These dialectical words and neologisms were utilized to present contextual viewpoints of the news and have assisted audiences to better appreciate and comprehend meaning in news broadcasting. Lastly, pedagogical significance was also given emphasis in the study. Hence, it can be said that language teachers may consider the application of the linguistic approach as a way to teach the intricacies of communication and journalism in written and spoken texts and help students determine explicit and implicit meanings by not confining the teaching of grammar to literal use but more significantly to functional use instead.

\section{References}

Adams, J. N. (2021). Asyndeton and its interpretation in Latin literature: History, patterns, textual criticism. Cambridge University Press.

Asif, M., Zhiyong, D., Iram, A., \& Nisar, M. (2021). Linguistic analysis of neologism related to coronavirus (COVID-19). Social Sciences \& Humanities Open, 4(1), 100201. https://doi.org/10.1016/j.ssaho.2021.100201

Battaglia, M. (2018). Study of rare sampling of the $b$ quark with the DELPHI detector at LEP. Helsinki: Yliopistopaino.

Blace, N. (2014). Study on good governance in General Santos City. Unpublished Research, General Santos City Police Office XII.

Cameron, L., Pelosi, A., \& Feltes, H. P. (2014). Metaphorizing violence in the UK and Brazil: A contrastive discourse dynamics study. Metaphor and Symbol, 29(1), 2343. https://doi.org/10.1080/10926488.2014.859048

Chiluwa, I. E. \& Blench, N. (2016). A critical study of language variation and ideological differences in media discourse in Nigeria. Ibadan Journal of English Studies, 87-175. http://dx.doi.org/10.18523/journal.v3i7.292

Croft, W. (2018). Evolutionary linguistics. Annual Review of Anthropology,37(1), 219. https://doi.org/10.1146/annurev.anthro.37.081407.085156

Crystal, D. (1969). An encyclopedia dictionary of language. Oxford Blackwell Publishers Linguistics. Penguin Books. ISBN 9780140135312.

Dijk, T. A. (1955). Discourse and communication: New approaches to the analysis of mass media discourse and communication. Berlin: W. de Gruyter.

Duan, Z., \& Xu, W. (2020). A study on the lexical features and value of Thai nursery rhymes. Proceedings of the 2020 Conference on Education, Language and Inter-cultural Communication (ELIC 2020). https://doi.org/10.2991/assehr.k.201127.098 
ADJES Vol 8. No.2 September 2021 p. 103-121

Fengjie, L. (2016). Analysis of the rhetorical devices in Obama's public speeches. International Journal of Language and Linguistics, 4(4), 141.

https://doi.org/10.11648/j.ijll.20160404.11

Fowler, R. (1991). Linguistic Criticism (2nd ed.). Oxford: OUP.

Galperin, I. R. (1977). Stylistics. Moscow: "Higher School". Retrieved from: https://www.academia.edu/34733554/DBE_Galperin_i_r_Stylistics [on 11 November 2015]

Golovko, N. (2019). Is a metonymy always a metonymy? A speculation on taxonomical aspects of propositional metonymy and situational metonymy. SHS Web of Conferences, 69, 00044. https://doi.org/10.1051/shsconf/20196900044

Harjule, P., Sharma, A., Chouhan, S., \& Joshi, S. (2020). Reliability of News. 2020 3rd International Conference on Emerging Technologies in Computer Engineering: Machine Learning and Internet of Things (ICETCE). https://doi.org/10.1109/ICETCE48199.2020.9091751

Houston, K (2013). Shady characters: The secret life of punctuation, symbols \& other typographical marks. New York \& London: W. W. Norton \& Company, Inc.

How cinematic metaphor opens up metaphor studies. Cinematic Metaphor in Perspective, 1735. https://doi.org/10.1515/9783110615036-002

Iswati, L., \& Widodo, P. (2020). Linguistic features in e-Commerce slogans. Indonesian Journal of EFL and Linguistics, 5(1), 21. https://doi.org/10.21462/ijefl.v5i1.211

Kholod, I. (2021). Basic Approaches to The Study of Repetition-Enumeration in Modern Linguistics. Magyar Tudomanyos Journal.

Labov, W. (2004). Discourse Reader, 229-241. https://doi.org/10.4324/9780203597071-26

Lakoff, G., \& Johnson, M. (2008). Metaphors we live by. University of Chicago Press.

Lavrakas, P. J. (2018). Encyclopedia of survey research methods. Sage Publications. DOI: Encyclopedia of Survey Research Method

Lippmann, D.N, et al (2002). Closing the gap: Addressing the vocabulary needs of Englishlanguage learners in bilingual and mainstream classrooms. Reading Research Quarterly, 39, 2, pp. 188-215. https://doi/10.1111/j.10.1598/RRQ.39.2.3

Lippmann, W. (1995). Public opinion. New York: Harcourt, Brace.

Lorenz, L. (2018, March 16). Why Journalists Should Use Data. Data Journalism. https://datajournalism.com/

Makhsetbaevna, K. Z. (2021). Phonosemantics of works by Jiyenbay Izbaskanov. ACADEMICIA: An International Multidisciplinary Research Journal, 11(6), 85-91. https://doi.org/10.5958/2249-7137.2021.01571.8

Mantra, D. I. (2021). Figurative language, symbolic meaning, and choice of diction in Matteppang Bibi' Ripangempange used by Buginese community. (Doctoral dissertation, HASANUDDIN UNIVERSITY). 
Mokhathi-Mbhele, M. M. (2020). Discourse of "Thing" as Sesotho personal names: A systemic functional linguistics approach. OALib, 07(07), 1-

12. https://doi.org/10.4236/oalib.1105783

Muslima, A. T. (2021). The usage of onomatopoeia sound symbol on book "Diary of a Wimpy Kid. English Language and Literature International Conference (ELLiC) Proceedings, 4, 283-290. https://jurnal.unimus.ac.id/index.php/ELLIC/article/viewFile/7417/5496

Muthalib, K. A., Fata, I. F., \& Rohaza, V. (2020). How stars stole all night away": a stylistic analysis of personification in movie trolls's soundtracks. Konferensi Linguistik Tahunan Atma Jaya, 1(1), 50-55.

Nastenko, 0. (2021). Phonics of poetic language in the aspect of idiostyle research. EDUCATION AND SCIENCE OF TODAY: INTERSECTORAL ISSUES AND DEVELOPMENT OF SCIENCES VOLUME2. https://doi.org/10.36074/logos-19.03.2021.v2.50

Nizomova, Z. (2021). Teachers' English Proficiency and classroom language use. Lacunalarning of linguomadanium ahamiyati. Journal of Foreign Languages and Linguistics, 2(3), 9296.

Nurmamatovich, J. Z., \& Abdurashidovna, K. N. (2021). The stylistic functions and types of zeugma. ACADEMICIA: An International Multidisciplinary Research Journal, 11(3), 3035. https://doi.org/10.5958/2249-7137.2021.00586.3

Pathak, A., Calvert, G. A., \& Motoki, K. (2021). Sound symbolism overrides articulation dynamics in the taste continuum. Food Quality and Preference, 91, 104186. https://doi.org/10.1016/j.foodqual.2021.104186

Pervukhina, S., \& Rood, E. (2021). Dynamics of emotivity in the newspaper style (in articles about COVID-19). E3S Web of Conferences, 273, 11044. https://doi.org/10.1051/e3sconf/202127311044

Sacco V.F. (1995). Media Constructions of Crime. The ANNALS of the American Academy of Political and Social Science. 1995;539(1):141-154. https://doi:10.1177/0002716295539001011

Smith, N. (2010). Acquiring phonology: A cross-generational case study. In the series Cambridge Studies in Linguistics 124. Cambridge: Cambridge University Press. Pp. xvii 265. Canadian Journal of Linguistics/Revue Canadienne De Linguistique, 59(2), 279-281. http://doi:10.1017/S0008413100000293

Spriggs, M. (2020). Story of 'us vs. Them': a critical discourse analysis of blame tactics in political campaign speeches. Hofstra University. ProQuest Dissertations.

Thacker, M., \& D'Angelo, C. (2019). Questions and exclamations. Essential French Grammar, 376-389. https://doi.org/10.4324/9780429441882-16

Timralieva, J. G. (2021). Zeugma as a method of pragmatic focusing in a literary text (Based on the material of the German language). Discourse, 7(2), 118126. https://doi.org/10.32603/2412-8562-2021-7-2-118-126

Unson, J. (2015, August 15). Police Regional Office 12 cops warn against involvement in crimes. Philippine Star 